This item was submitted to Loughborough's Research Repository by the author.

Items in Figshare are protected by copyright, with all rights reserved, unless otherwise indicated.

\title{
A new copula-based standardized precipitation evapotranspiration streamflow index for drought monitoring
}

PLEASE CITE THE PUBLISHED VERSION

https://doi.org/10.1016/j.jhydrol.2020.124793

PUBLISHER

Elsevier BV

VERSION

AM (Accepted Manuscript)

PUBLISHER STATEMENT

This paper was accepted for publication in the journal Journal of Hydrology and the definitive published version is available at https://doi.org/10.1016/j.jhydrol.2020.124793.

LICENCE

CC BY-NC-ND 4.0

\section{REPOSITORY RECORD}

Wang, Fei, Zongmin Wang, Haibo Yang, Danyang Di, Yong Zhao, and Qiuhua Liang. 2020. "A New Copulabased Standardized Precipitation Evapotranspiration Streamflow Index for Drought Monitoring”. Loughborough University. https://hdl.handle.net/2134/12630188.v1. 


\section{A new copula-based standardized precipitation}

\section{2 evapotranspiration streamflow index for drought}

\section{3 monitoring}

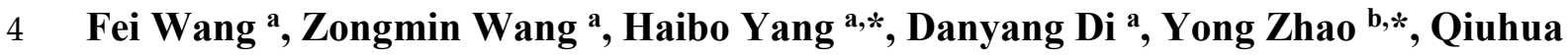

$5 \quad$ Liang ${ }^{\mathbf{c}}$

a School of Water Conservancy and Environment, Zhengzhou University, Zhengzhou 
effectively; (2) the seasonal and annual droughts were increasing in the YRB during 1961-2015, with different temporal change characteristics in each subzone; (3) the month and season with the most serious drought was June and summer, with an average SPESI value of -1.23 and -0.89 , respectively; (4) Frank-copula was considered to be the best-fitted copula function in the YRB; and (5) the cross wavelet transform illustrated that teleconnection factors had strong influences on the evolution of drought in the YRB, and the impacts of El Niño-Southern Oscillation (ENSO), Arctic Oscillation (AO) and sunspot on the droughts were stronger than those of Pacific Decadal Oscillation (PDO). This study can provide a reliable and effective multivariate index for drought monitoring, which can also be applied in other regions.

Keywords: SPESI; Drought; Copula; Cross wavelet transform; Yellow River Basin

\section{Introduction}

Drought is a complex problem that restricts the development of human society and economy, which has the characteristics of high frequency, wide influence and serious damage (Mishra and Singh, 2010; AghaKouchak et al., 2015; Zhang et al., 2017; Montaseri et al., 2018). Drought not only endangers crop growth and reduces crop yields, but also imperils people's lives and affects industrial production and other social and economic activities. With the phenomenon of global warming, the frequency and impact of drought are increasing gradually; thus, it is of great significance to make a profound investigation on drought. China has experienced frequent drought disasters, which seriously affects the country's agricultural production, economic development and social stability (Ayantobo et al., 2018; Yao et al., 2018). In order to further quantify drought, researchers often apply meteorological and hydrological factors that affect drought to establish different drought indices, and objectively compare drought duration, severity, frequency and impact on spatial and temporal scales, so as to achieve the purpose of synthetically measuring, 
evaluating and studying drought (Marcos-Garcia et al., 2017; Oloruntade et al., 2017). Meanwhile, in view of different types of drought, researchers have constructed various drought indices, including the Standardized Precipitation Evapotranspiration Index (SPEI) for describing meteorological drought and the Standardized Streamflow Index (SSI) for investigating hydrological drought (Vicente-Serrano et al., 2010; Shukla and Wood, 2008). The SPEI and SSI have been used to do various researches in different regions. For example, Tirivarombo et al. (2018) compared the drought monitoring effects of SPEI and Standardized Precipitation Index (SPI) in the Kafue basin, and found that SPEI had better drought description ability than SPI because of considering the factor of evapotranspiration. Zhao et al. (2017) discovered that SPEI was appropriate for both short- and long-term drought monitoring and should have greater application prospects in China. Rivera et al. (2017) concluded that SSI can accurately reflect the evolution characteristics of extreme hydrological drought across the Central Andes, Argentina. Chen et al. (2018) adopted SSI to verify that hydrological drought had increased significantly in the past decades in the Luanhe River Basin.

Although drought indices can reflect drought situation from a certain perspective, there are some discrepancies among drought-related meteorological and hydrological variables. It is difficult to comprehensively reflect the complexity and extensiveness of drought impacts on social life by evaluating drought severity only from one factor of drought formation or one representation of drought characteristics (Salvadori and De Michele, 2015; Huang et al., 2015a). Because of the different emphasis of drought indices, different departments adopt various indices for drought assessment, and drought monitoring and analysis only by a single index cannot fully reflect the comprehensive effects caused by drought. Additionally, drought has complex causes and different external performances and impacts, thus, it is necessary to explore a multivariable method to systematically and comprehensively understand and evaluate drought from multiple perspectives (Rajsekhar et 
al., 2015; Waseem et al., 2015). In recent years, most scholars have made considerable efforts to establish comprehensive drought indices that integrate multiple drought-related variables. Waseem et al. (2015) developed a new composite drought index for multivariate drought assessment based on the entropy weighted Euclidian distance. Huang et al. (2015b) combined SPI and SSI to construct an integrated drought index by using entropy weight method. Liu et al. (2019) proposed an aggregate drought index integrating precipitation, evapotranspiration, soil moisture, runoff and other hydrometeorological factors based on the principal component analysis method (PCA).

However, the comprehensive drought indices based on entropy weight and PCA method combine the drought-related variables linearly and cannot reflect their non-linear structural characteristics. Copula function can combine multiple drought characteristic variables based on the correlation among variables, which is more superior than traditional multivariate analysis method and has been widely used in hydrometeorological field (Kao and Govindaraju, 2010; Lee et al., 2013; Maeng et al., 2017; Vyver and Bergh, 2018). In addition, copula is suitable for constructing joint distribution of arbitrary marginal distribution function and has the characteristics of flexibility, convenience and wide application, which provides a new approach for multivariate analysis of drought. Hao and AghaKouchak (2013) applied copula to construct a parameterized multivariate standardized drought index, and indicated that the proposed index was shown to be a reasonable drought monitoring instrument for combining multiple indices probabilistically. Guo et al. (2019a) proposed an improved multivariate standardized reliability and resilience index to assess socio-economic drought risk based on copula, and the results shed new insights into socioeconomic drought dynamic risk assessment in a changing environment.

Meteorological drought mainly refers to the phenomenon of water shortage in which precipitation and evapotranspiration are unbalanced over a period of time (Shahabfar and Eitzinger, 2013; Wang et al., 2018). Long-term meteorological drought will lead to 
hydrological drought. Hydrological drought is caused by the low water availability in rivers, underground aquifers and other water bodies (Mondal and Mujumdar, 2015; Oloruntade et al., 2017). Since the rapid occurrence and termination of meteorological drought caused by the decrease of precipitation and the increase of temperature, the response of hydrological drought characterized by insufficient runoff to meteorological drought has a certain time-lag effect (Mishra and Singh, 2010; Rivera et al., 2017). Therefore, we should develop a comprehensive drought index which can simultaneously characterize the characteristics of meteorological and hydrological drought to improve the accuracy and applicability of drought monitoring, so as to provide powerful support for policy makers in mitigating and preventing drought (Makokha et al., 2016; Huang et al., 2019). In view of this, this paper took the Yellow River Basin (YRB), which is more vulnerable to drought disasters in northern China, as the research area. A copula-based Standardized Precipitation Evapotranspiration Streamflow Index (SPESI) was first introduced, which combined meteorological drought index SPEI and hydrological drought index SSI. The joint distribution functions of SPEI and SSI were constructed to overcome the subjectivity of comprehensive drought index based on entropy weight method and the distortion of non-linear related variables based on principal component analysis method. The proposed SPESI contains precipitation, evapotranspiration and streamflow information, which combines the advantages of SPEI in capturing the occurrence of drought and SSI in detecting the termination of drought, and can synthetically characterize the characteristics of meteorological and hydrological drought.

The primary objectives of this study are (1) to calculate SPEI and SSI based on the optimal marginal distribution function; (2) to introduce a new copula-based comprehensive drought index SPESI, which combines the advantages of SPEI and SSI and can simultaneously reflect both meteorological and hydrological drought; (3) to identify the temporal change, spatial distribution and return period of drought based on SPESI in the 
YRB during 1961-2015; and (4) to reveal the links between SPESI and teleconnection factors using cross wavelet transform method. The research results can provide a more reasonable and favourable index for drought monitoring, which can also be applied in other study areas.

\section{Study area and data}

As the second longest river in China and the fifth longest river in the world, the Yellow River is the mother river of the Chinese people and the main origination of Chinese civilization. The total length of the main stream of the Yellow River is $5464 \mathrm{~km}$, with a total drainage area of $795,000 \mathrm{~km}^{2}$. As an important agricultural production base in China, the YRB is also a sensitive and vulnerable area affected by climate change, with frequent and serious drought in history (She and Xia, 2013; Zhang et al., 2016). Due to the influence of atmospheric circulation and monsoon climate, the precipitation distribution is significantly heterogeneous in the YRB, and it decreases gradually from southeast to northwest with uneven seasonal distribution characteristics. Annual precipitation varies from 123 to $1021 \mathrm{~mm}$, and annual evaporation varies from 700 to $1800 \mathrm{~mm}$ in the YRB (Wang et al., 2019a). The temperature is higher in the south and east, and lower in the north and west, with an average annual temperature ranging from -4 to $14{ }^{\circ} \mathrm{C}$. Because of its large geographical scope, the YRB can be divided into seven subzones, including above Longyangxia (AL), Longyangxia to Lanzhou (LL), Lanzhou to Hekou (LH), Hekou to Longmen (HL), Longmen to Sanmenxia (LS), Sanmenxia to Huayuankou (SH) and below Huayuankou (BH).

Monthly precipitation and temperature data from 124 meteorological stations during 1961-2015 were obtained from the National Meteorological Information Center at the China Meteorological Administration (CMA) (http://data.cma.cn/). It can be seen from Fig. 1 that the 124 meteorological stations are distributed evenly in the YRB. Additionally, the 
154 homogeneity and reliability of the meteorological data were checked by the CMA before

155 their release, and the data showed excellent homogeneity under strict quality control.

156 Monthly streamflow data of seven typical hydrological stations (Tangnaihai, Lanzhou,

157 Toudaoguai, Longmen, Sanmenxia, Huayuankou and Lijin) in the main stream of the YRB

158 during 1961-2015 were obtained from the Hydrological Bureau of the Yellow River Water

159 Conservancy Commission. The selected seven hydrological stations are located

160 downstream of each catchment area, so they can reflect the hydrological information of

161 different catchment areas (AL, LL, LH, HL, LS, SH and BH) (Fu et al., 2004). Moreover,

162 monthly climate data covering 1961 to 2015 were also applied, including the El

163 Niño-Southern Oscillation (ENSO), the Pacific Decadal Oscillation (PDO), the Arctic

164 Oscillation (AO) and sunspot data (Su et al., 2017; Han et al., 2019; Guo et al., 2019b). For

165 ENSO, we selected Niño 3.4 index obtained from the National Oceanic and Atmospheric

166 Administration (NOAA) Earth System Research Laboratory

167 (http://www.esrl.noaa.gov/psd/data/correlation/nina34.data). Similarly, the monthly PDO

168 data were derived from the NOAA Earth System Research Laboratory

169 (http://www.esrl.noaa.gov/psd/data/correlation/amon.us.long.data). The monthly AO data

170 were obtained from the NOAA National Climatic Data Center

171 (http://www.ncdc.noaa.gov/teleconnections/ao.php). Regarding sunspot, its monthly data

172 were obtained from the Royal Observatory of Belgium (http://www.sidc.be/sunspot-data). 


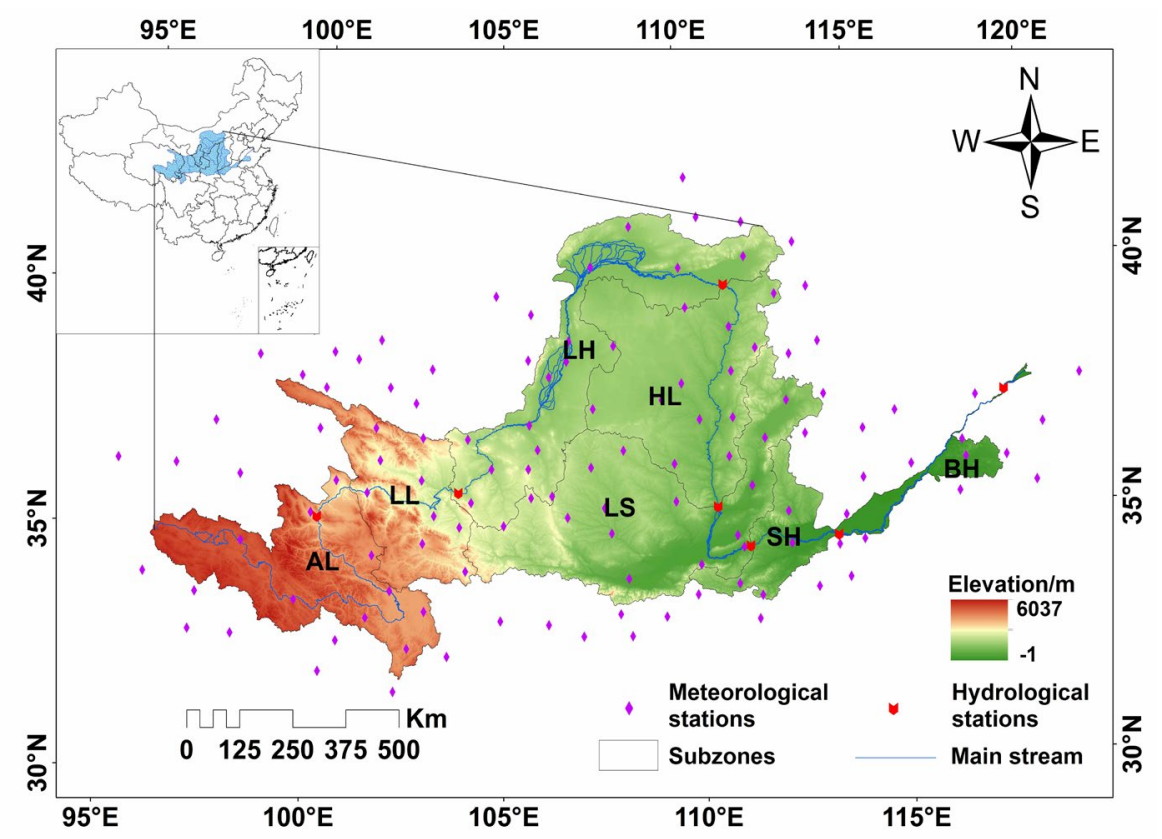

Fig. 1. Spatial distributions of the meteorological and hydrological stations in the YRB.

\section{Methodology}

\subsection{Standardized precipitation evapotranspiration index (SPEI) and standardized} streamflow index (SSI)

The SPEI was selected as a meteorological drought index in this study, which combined the advantages of the Palmer Drought Severity Index and SPI. SPEI has the characteristics of spatial comparability and multi-time scale, and it has good application prospects (Vicente-Serrano et al., 2010; Alam et al., 2017; Tirivarombo et al., 2018). Considering the factor of temperature, SPEI can well reflect the drought caused by the rapid rise of temperature. For this study potential evapotranspiration (PET) is estimated by the Thornthwaite method. Thornthwaite method has relatively simple calculation and needs less meteorological factors, which does not require substantial input data. Previous studies (Yu et al., 2014; Zhao et al., 2017; Wang et al., 2018) have demonstrated that thornthwaite method is feasible and effective, and has been widely used in the SPEI calculation. The calculation procedure of SPEI is described in Tirivarombo et al. (2018). 
The SSI was chosen as a hydrological drought index, and its calculation process was

similar to that of the SPI. It is worth noting that because of the large geographic range of the YRB, the streamflow distributions will show regional differences due to the influence of climatic factors and human activities. Hence, considering the accuracy of the results, the optimal distribution function of streamflow should be selected to calculate SSI (Telesca et al., 2012; Vicente-Serrano et al., 2012; Bloomfield and Marchant, 2013). Similarly, in the calculation process of SPEI, it is also necessary to select the optimal distribution function of the difference between precipitation and potential evapotranspiration (P-PET). Six three-parameter Pearson Type III (P-III), Log-Logistic (Log-L), Weibull (Wbl), Generalized Pareto (GP), General Extreme Value (GEV) and Lognormal (Logn) distributions were adopted to determine the optimal distribution function (Hosking et al., 1985; Hosking, 1986, 1990; Singh et al., 1993; Vicente-Serrano et al., 2012). These distributions were selected because they could accommodate all magnitudes of non-negative skewness from zero to severe. Additionally, the Kolmogorov-Smirnov (K-S), Anderson-Darling (A-D) and Akaike Information Criterion (AIC) test method were adopted to test the fitting result when selecting distribution function (Sherly et al., 2016). The detailed procedures can be referred to Vicente-Serrano et al. (2012).

\subsection{Copula-based standardized precipitation evapotranspiration streamflow index (SPESI)}

Copula function can combine the joint distribution function of multiple variables with their respective marginal distribution function, and can construct the joint distribution of multiple different marginal distributions (Hao and AghaKouchak, 2013). After calculating SPEI and SSI, the marginal distribution functions of SPEI and SSI were combined to construct a new drought index SPESI based on copula function. Firstly, the above six distributions (P-III, Log-L, Wbl, GP, GEV and Logn) were selected to determine the marginal distribution function of SPEI and SSI. Similarly, the K-S, A-D and AIC test method were adopted to determine the optimal marginal distribution function. Then, five 
commonly used copula functions (Normal-copula, t-copula, Clayton-copula, Frank-copula and Gumbel-copula) were selected as joint functions to construct the joint distribution of SPEI and SSI (Guo et al., 2019a). Copula functions used in this study are described in Table 1. The goodness of fit (GOF) of the copula function was tested based on the root mean square error (RMSE), AIC, and Bayesian Information Criterion (BIC) between the empirical and theoretical distribution function (Masud et al., 2015; Fan et al., 2018). Noticeably, the maximum likelihood estimation method was used to estimate the parameters of the univariate and bivariate distribution function in this paper. Finally, the SPEI and SSI sequences were taken as random variables $x$ and $y$, and $F(x)$ and $G(x)$ were considered as the corresponding marginal distribution functions of these two random variables. Thus, the joint distribution $P$ of the two variables could be expressed using cumulative joint probability $p$ and copula function $C$ :

$$
P(x \leq X, y \leq Y)=C[F(x), G(x)]=p
$$

Then, the SPESI was calculated based on cumulative joint probability $p$ :

$$
\text { SPESI }=\varphi^{-1}(p)
$$

where $\varphi$ is the standard normal distribution, and $p$ is the cumulative joint probability. Similar to the SPEI and SSI, the SPESI is derived from the joint probability of the variables of interest, which can be used to investigate droughts at multiple time scales (e.g., 3, 6, 9, 12 and 24 month time scale). Although we take a 1-month time scale as an example, which is very important for us to timely grasp the drought information and make reasonable responses, other time scales can also be calculated. In order to investigate the SPESI at multiple time scales, SPEI and SSI are computed for the same durations. Because the calculation principles of the SPESI are similar to those of the SPEI and SSI, the SPESI adopts the same grade standard as the SPEI and SSI, as shown in Table 2. 


\begin{tabular}{cccc}
\hline Name & Mathematical Description & Parameter Range & Reference \\
\hline Normal-copula & $\int_{-\infty}^{\Phi^{-1}(u)} \int_{-\infty}^{\Phi^{-1}(v)} \frac{1}{2 \pi \sqrt{1-\theta^{2}}} \exp \left(\frac{2 \theta x y-x^{2}-y^{2}}{2\left(1-\theta^{2}\right)}\right) d x d y$ & $\theta \in[-1,1]$ & (Li et al., 2013) \\
t-copula & $\int_{-\infty}^{t_{9}^{-1}(u)} \int_{-\infty}^{t_{\vartheta}^{-1}(v)} \frac{\Gamma((\vartheta+2) / 2)}{\Gamma(\theta / 2) \pi \vartheta \sqrt{1-\theta^{2}}}\left(1+\frac{x^{2}-2 \theta x y+y^{2}}{\vartheta}\right)^{(\vartheta+2) / 2} d x d y$ & $\theta \in[-1,1]$ & (Li et al., 2013) \\
Clayton-copula & $\left(u^{-\theta}+v^{-\theta}-1\right)^{-1 / \theta}$ & $\theta \in[0, \infty)$ & (Li et al., 2013) \\
Frank-copula & $-\frac{1}{\theta} \ln \left(1+\frac{\left(e^{-\theta u}-1\right)\left(e^{-\theta v}-1\right)}{e^{-\theta}-1}\right)$ & $\theta \in R \backslash 0$ & (Li et al., 2013) \\
Gumbel-copula & $\exp \left(-\left((-\ln u)^{\theta}+(-\ln v)^{\theta}\right)^{1 / \theta}\right)$ & $\theta \in[1, \infty)$ & (Li et al., 2013) \\
\hline
\end{tabular}

$242 \quad$ Table 2

243 Classification of the SPEI, SSI and SPESI used in this study.

\begin{tabular}{ccc}
\hline Grade & Classification & SPEI, SSI, SPESI Values \\
\hline 1 & No drought & $-0.5<$ Index \\
2 & Mild drought & $-1.0<$ Index $\leqslant-0.5$ \\
3 & Moderate drought & $-1.5<$ Index $\leqslant-1.0$ \\
4 & Severe drought & $-2.0<$ Index $\leqslant-1.5$ \\
5 & Extreme drought & Index $\leqslant-2.0$ \\
\hline
\end{tabular}

3.3. The modified Mann-Kendall (MMK) trend test method

The traditional Mann-Kendall (MK) trend test method is a nonparametric technique to

246 identify the trend characteristics of time series. However, due to the autocorrelation of time series, the significance of the results obtained by MK method will be affected (Wang et al., 2019b). The modified Mann-Kendall (MMK) trend test method can eliminate the autocorrelation of time series and improve the detection ability of MK method. Therefore, this paper adopted MMK method to identify the temporal variation trend of drought in the YRB from 1961 to 2015. The detailed computational processes can be referred to Guo et al. (2019b).

\subsection{Return period}

In this study, two principal characteristic variables of drought events, drought duration

255 and severity, were identified from the calculated SPESI series using run theory, and then the joint return period of drought duration and severity was obtained based on copula 
function. Drought duration represents the period of a drought event from its occurrence to termination, and drought severity indicates the influence degree of a drought event (Montaseri et al., 2018; Wang et al., 2019a). The drought return period based on copula function can quantitatively reveal the frequency of drought events, and well characterize the impacts and characteristics of drought events (Ayantobo et al., 2018). The specific identification process of drought return period can be referred to Wang et al. (2019a).

\subsection{Cross wavelet transform method}

Cross wavelet transform method is a new multi-signal and multi-scale analysis technology based on traditional wavelet analysis. It can not only effectively analyze the correlation between two time series, but also reflect the phase structure and detail features of the two time series in both time and frequency domains (Hudgins and Huang, 1996; Huang et al., 2015a). Furthermore, cross wavelet transform combines wavelet transform and cross spectrum analysis, which can demonstrate the correlation between two time series in time and frequency domains, and show good application prospect in hydrological time series analysis. In this study, the links between SPESI and teleconnection factors were investigated in the YRB using cross wavelet transform method. The cross wavelet transform of the two time series $x_{n}$ and $y_{n}$ can be described as $W^{X Y}=W^{X} W^{Y *}$, where $*$ reveals their complex conjugation. The cross wavelet power is expressed as $\left|W^{X Y}\right|$. The complex $\operatorname{argument} \arg \left(W^{x y}\right)$ can be regarded as the local relative phase between $x_{n}$ and $y_{n}$ in time and frequency domains. The theoretical distribution of the cross wavelet power of the two time series with their background power spectra $P_{k}^{X}$ and $P_{k}^{Y}$ is expressed as follows:

$$
D\left(\left|\frac{W_{n}^{X}(s) W_{n}^{Y *}(s)}{\sigma_{X} \sigma_{Y}}\right|<p\right)=\frac{Z_{v}(p)}{v} \sqrt{P_{k}^{X} P_{k}^{Y}}
$$


where $Z_{v}(p)$ is the confidence level associated with the probability $p$ of a probability distribution function which is defined by the square root of two $\chi^{2}$ distributions (Torrence and Compo, 1998).

\section{Results}

\subsection{Construstion of the SPESI}

In this study, the meteorological drought index SPEI and hydrological drought index SSI were firstly calculated. Then, a new copula-based drought index SPESI was proposed, which could represent both meteorological and hydrological drought. Before calculating SPEI and SSI, the calculation steps were slightly improved. The monthly P-PET and streamflow data used for calculating SPEI and SSI were fitted respectively, so that the calculated SPEI and SSI based on the selected optimal distribution function had better mathematical and statistical theory basis. Therefore, six three-parameter distributions (P-III, Log-L, Wbl, GP, GEV and Logn) were adopted, in order to determine the optimal distribution functions of monthly P-PET and streamflow data. Figs. 2-3 show the empirical probability-theoretical probability (P-P) plot of P-PET and streamflow in the YRB for each month, which is nearly a line. This suggests that the selected distribution function is able to fit P-PET and streamflow data very well, and can be utilized to calculate SPEI and SSI accurately in the YRB. Specifically, the optimal distributions of P-PET and streamflow data were different in each month, and most of the selected distribution functions were Log-L and GEV distributions. Similarly, the optimal distribution functions of P-PET and streamflow data in each subzone were determined to calculate the SPEI and SSI sequences in each subzone of the YRB. 

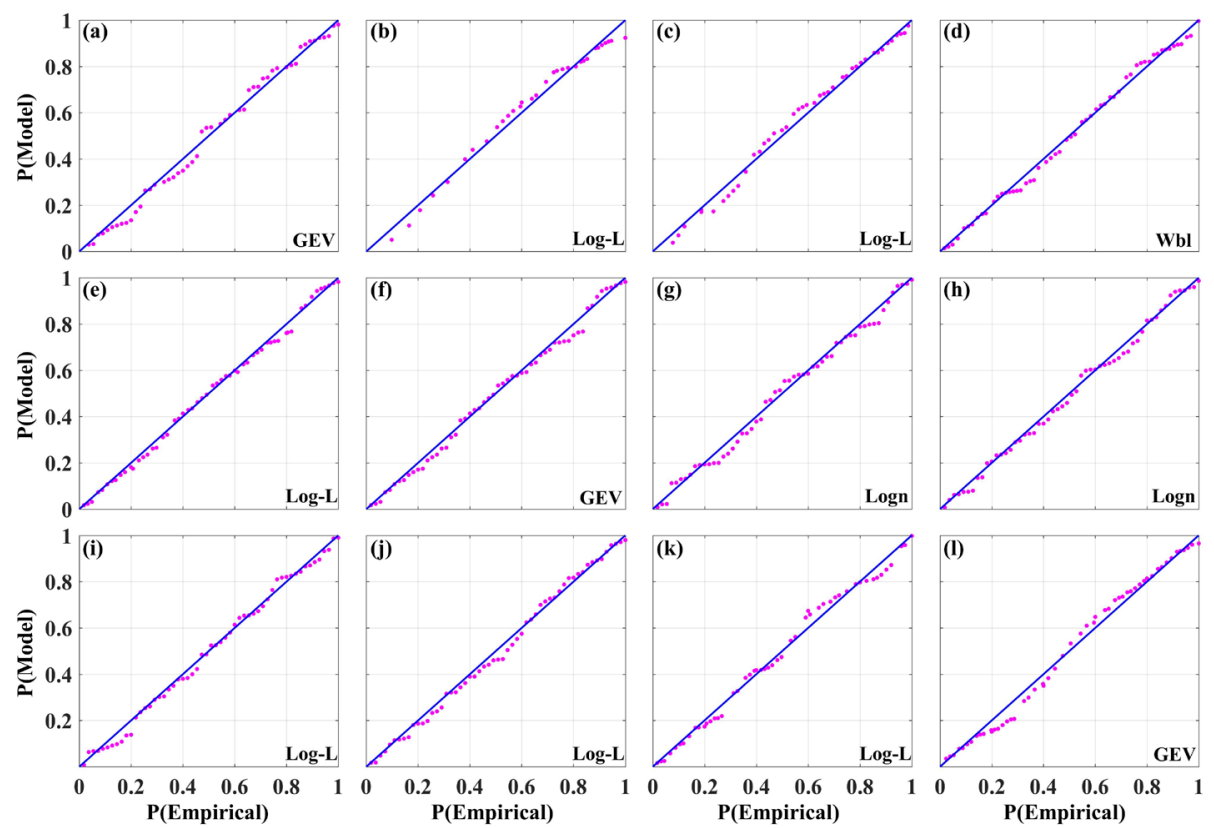

Fig. 2. P-P plot of P-PET for calculating SPEI in the YRB. (a)-(l) denote January, February, March, April, May, June, July, August, September, October, November and December, respectively.
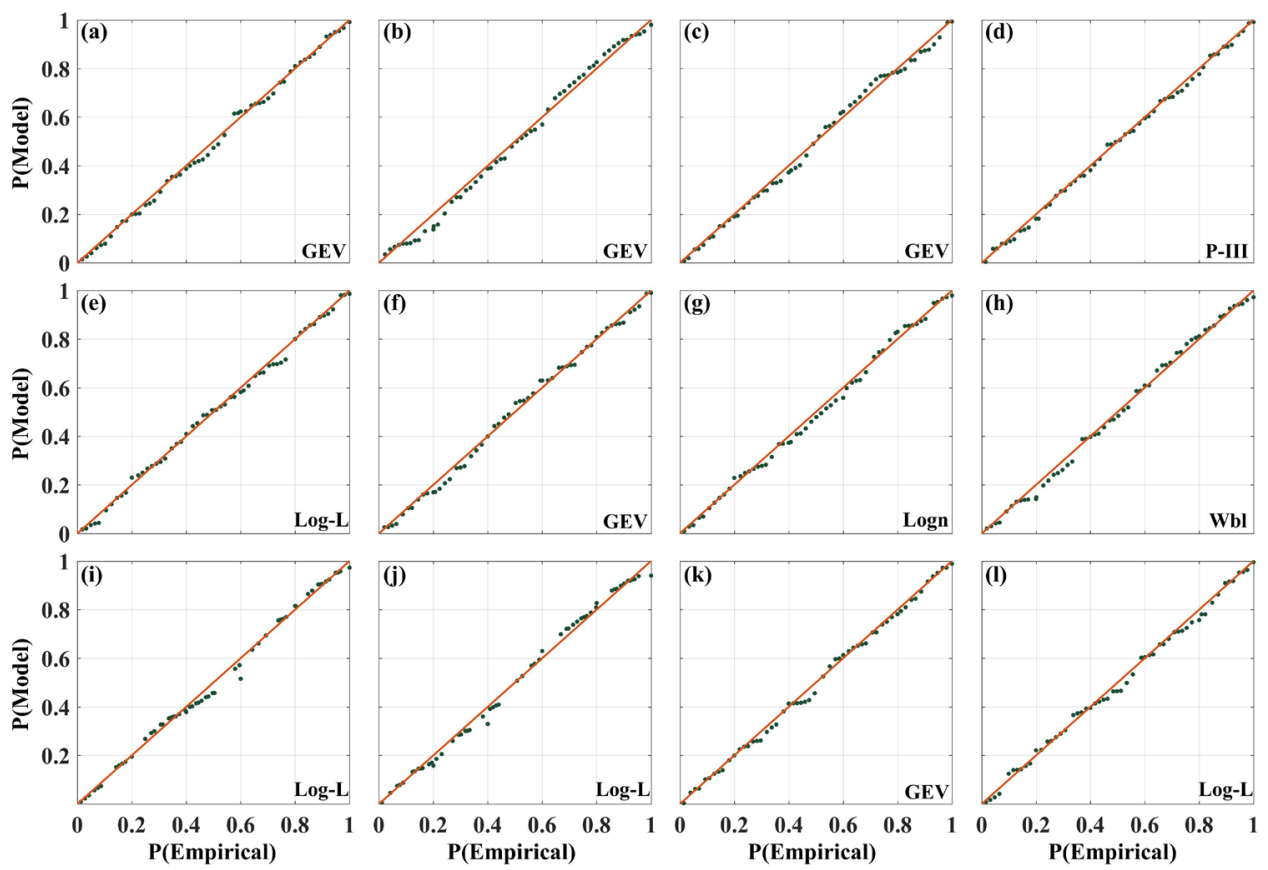

Fig. 3. P-P plot of streamflow for calculating SSI in the YRB. (a)-(1) denote January, February, March, April, May, June, July, August, September, October, November and December, respectively. 
After calculating SPEI and SSI, the SPESI can be constructed according to Eqs.

310 (1)-(2). Noticeably, the Kendall rank correlation coefficient $(\tau)$ and Spearman rank

311 correlation coefficient $\left(\rho_{s}\right)$ between SPEI and SSI passed the significance test of $\alpha=0.01$ in

312 the YRB (Table 3), suggesting that SPEI and SSI had high correlations and a new

313 copula-based drought index SPESI could be constructed. The GOF test of copula function

314 was carried out by calculating the RMSE, AIC and BIC values between empirical and

315 theoretical copula functions. Based on the principle that the smaller the RMSE, AIC and

316 BIC values, the higher the GOF of copula function, all the GOF evaluation indicators of the

317 selected optimal copula meet the requirements (Table 4). As shown in Table 4, the optimal

318 copula function was Frank-copula for five subzones (AL, LH, HL, LS and SH) and the

319 entire basin (YRB), and was Normal-copula for the other two subzones (LL and BH). Fig. 4

320 indicates the P-P plot of the empirical and theoretical copula function, which is also nearly

321 a line. Therefore, the SPESI can be obtained based on the selected optimal copula function

322 that complies with the requirements.

323 Table 3

324 The Kendall and Spearman rank correlation coefficient between SPEI and SSI.

325

326

327

328

\begin{tabular}{ccccccccc}
\hline Rank correlation coefficient & AL & LL & LH & HL & LS & SH & BH & YRB \\
\hline Kendall $\tau$ & 0.66 & 0.59 & 0.55 & 0.59 & 0.66 & 0.61 & 0.61 & 0.61 \\
Spearman $\rho_{s}$ & 0.74 & 0.63 & 0.57 & 0.63 & 0.73 & 0.66 & 0.66 & 0.67 \\
\hline
\end{tabular}

\section{Table 4}

Goodness of fit (GOF) evaluation of different copula functions in the YRB. The bold letters represent the most appropriate copula which was selected to fit the joint distributions of SPEI and SSI.

\begin{tabular}{|c|c|c|c|c|c|c|c|c|c|c|c|c|c|c|c|c|}
\hline \multirow{2}{*}{ Zone } & \multicolumn{3}{|c|}{ Normal-copula } & \multicolumn{3}{|c|}{ t-copula } & \multicolumn{3}{|c|}{ Clayton-copula } & \multicolumn{3}{|c|}{ Frank-copula } & \multicolumn{3}{|c|}{ Gumbel-copula } & \multirow{2}{*}{$\theta$} \\
\hline & RMSE & $\mathrm{AIC}$ & $\mathrm{BIC}$ & RMSE & $\mathrm{AIC}$ & $\mathrm{BIC}$ & RMSE & $\mathrm{AIC}$ & $\mathrm{BIC}$ & RMSE & AIC & $\mathrm{BIC}$ & RMSE & AIC & $\mathrm{BIC}$ & \\
\hline AL & 0.06 & -381.95 & -380.50 & 0.06 & -382.01 & -381.11 & 0.07 & -355.05 & -354.61 & 0.05 & -383.05 & -382.60 & 0.06 & -380.85 & -380.40 & 5.02 \\
\hline LL & 0.03 & -454.53 & -454.08 & 0.03 & -454.26 & -453.36 & 0.04 & -433.56 & -433.11 & 0.04 & -450.16 & -449.71 & 0.04 & -444.99 & -444.54 & 0.62 \\
\hline LH & 0.05 & -388.98 & -388.53 & 0.05 & -388.78 & -387.88 & 0.06 & -380.82 & -380.37 & 0.05 & -392.96 & -392.51 & 0.05 & -387.59 & -387.14 & 1.49 \\
\hline HL & 0.04 & -437.93 & -437.48 & 0.04 & -438.45 & -437.55 & 0.04 & -417.90 & -417.45 & 0.03 & -440.64 & -440.19 & 0.04 & -430.09 & -429.64 & 2.21 \\
\hline LS & 0.04 & -436.49 & -436.04 & 0.04 & -437.47 & -436.57 & 0.04 & -423.32 & -422.87 & 0.03 & -443.11 & -442.66 & 0.04 & -422.68 & -422.23 & 3.05 \\
\hline
\end{tabular}




\begin{tabular}{|c|c|c|c|c|c|c|c|c|c|c|c|c|c|c|c|c|}
\hline SH & 0.03 & -442.64 & -442.19 & 0.03 & -444.10 & -443.20 & 0.04 & -423.77 & -423.32 & 0.03 & -449.62 & -449.17 & 0.03 & -432.61 & -432.16 & 2.73 \\
\hline $\mathrm{BH}$ & 0.03 & -464.39 & -463.94 & 0.03 & -462.63 & -461.73 & 0.03 & -450.02 & -449.57 & 0.03 & -454.54 & -454.10 & 0.03 & -462.00 & -461.55 & 0.23 \\
\hline YRB & 0.05 & -405.25 & -404.80 & 0.05 & -406.42 & -405.52 & 0.05 & -392.56 & -392.11 & 0.04 & -412.39 & -411.94 & 0.05 & -388.69 & -388.24 & 4.10 \\
\hline
\end{tabular}
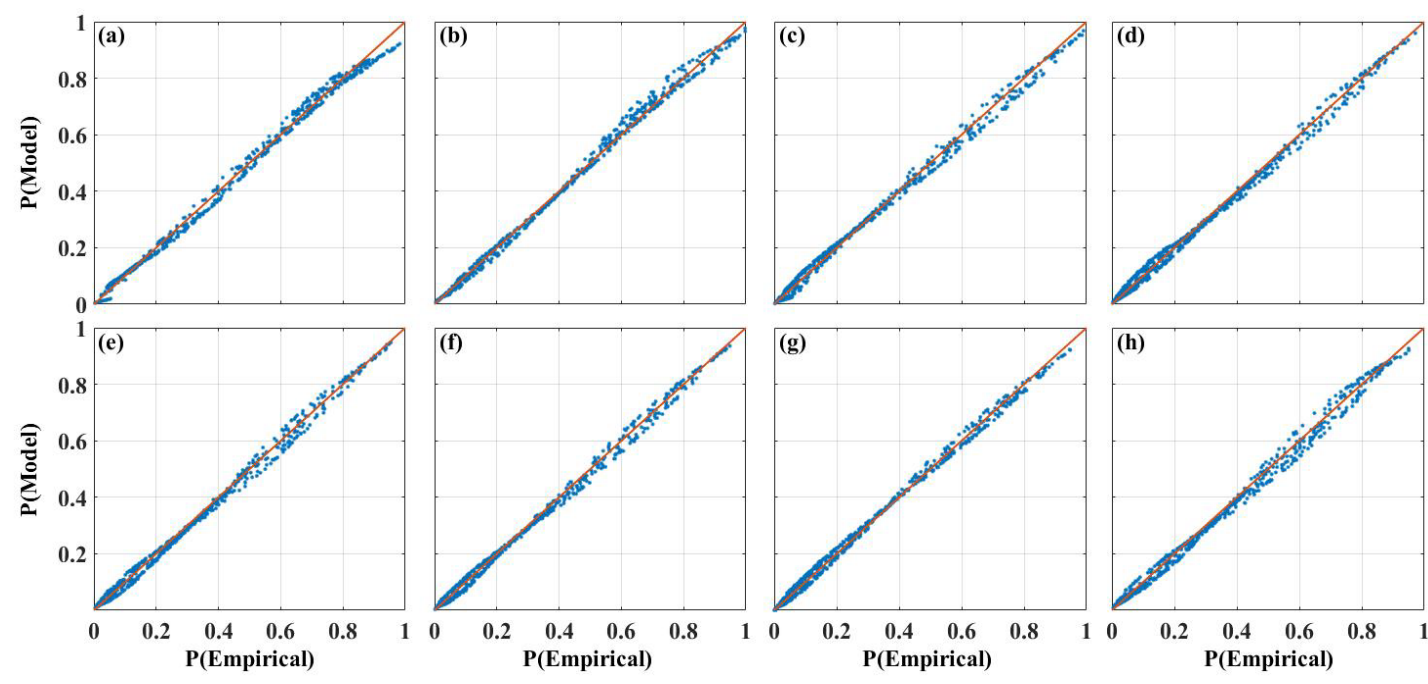

Fig. 4. P-P plot of empirical and theoretical copula function for calculating SPESI in the YRB. (a)-(h) denote AL (Frank-copula), LL (Normal-copula), LH (Frank-copula), HL (Frank-copula), LS (Frank-copula), SH (Frank-copula), BH (Normal-copula) and YRB (Frank-copula), respectively.

\subsection{Performance of the constructed SPESI}

In this study, we verified the superiority of SPESI in characterizing drought by comparing SPEI, SSI and SPESI in the YRB. Wang et al. (2018) pointed out that the most serious drought occurred in the period of 1997-2002 during recent decades in the YRB. Thus, the application effect of SPESI was verified by analyzing the variations of monthly SPEI, SSI and SPESI during this period (1997-2002). Considering that drought will have a greater impact only when it reaches a certain threshold, we define -0.8 as a threshold to determine the onset of drought (Hao and AghaKouchak, 2013; Guo et al., 2019a). As shown in the black rectangular boxes a, e and $\mathrm{f}$ in Fig. 5, the performance of SPESI in determining drought onset is similar to that of SPEI, and that the performance of SPESI in capturing drought persistence and termination is similar to that of SSI. This is because SPEI mainly reflects the characteristics of meteorological drought, and meteorological drought 
occurs and ends quickly. In addition, SSI mainly clarifies the features of hydrological drought, which lasts for a long time and has a delayed effect compared with meteorological drought. SPESI contains the advantages of SPEI in identifying the occurrence of drought and SSI in capturing the termination of drought. Moreover, rectangular box c indicates the condition under which only hydrological drought occurs, and rectangular box d denotes the situation under which only meteorological drought occurs (Fig. 5). Clearly, when either SPEI or SSI identifies a drought event, SPESI will also detect it. At the early stage of drought in the middle of 1998 (see rectangular box b in Fig. 5), although neither of the SPEI and SSI values reaches the threshold of drought, however, a drought in an integrated manner has already emerged. Subsequently, both indicators are decreasing and show signs of deficit. These results strongly demonstrate that SPESI integrates meteorological and hydrological information, which can capture the occurrence, duration and termination of drought sensitively and effectively.

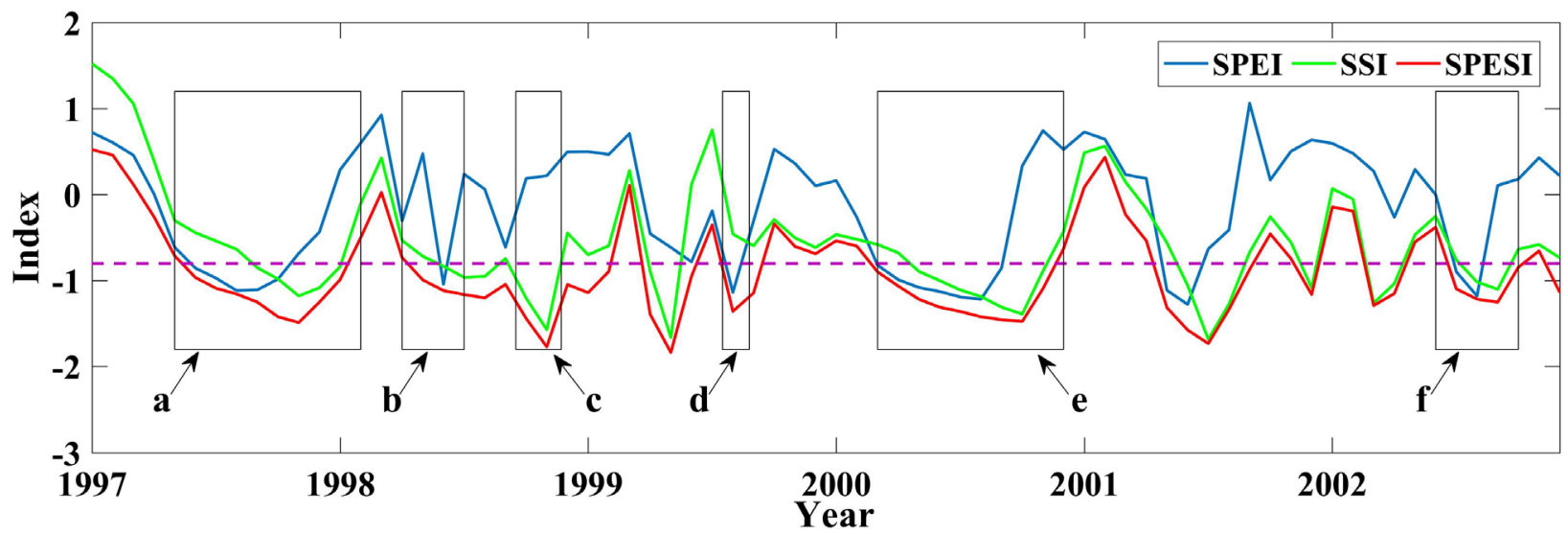

Fig. 5. Comparison between SPESI, SPEI and SSI series covering 1997-2002 in the YRB.

The spatial distribution of correlations between SPESI and SPEI is shown in Fig. 6. Noticeably, the Pearson correlation coefficient $(r)$ is 0.266 at the significance level of $\alpha=0.05$, and is 0.345 at the significance level of $\alpha=0.01$. On the monthly scale, the minimum $r$ between SPESI and SPEI appeared in LH (0.49) in January, and the maximum $r$ appeared in AL (0.88) in June. On the seasonal scale, the minimum $r$ appeared in AL 
(0.28) in autumn, and the maximum $r$ appeared in LH (0.69) in winter. Fig. 7 indicates the spatial distribution of correlations between SPESI and SSI. On the monthly scale, the minimum $r$ between SPESI and SSI appeared in AL (0.52) in March, and the maximum $r$ appeared in LS (0.89) in September. On the seasonal scale, the minimum $r$ appeared in LS (0.49) in winter, and the maximum $r$ appeared in LS (0.93) in autumn. Obviously, SPESI had a good correlation with SPEI and SSI, and the $r$ between SPESI and SSI was generally higher than that between SPESI and SPEI. Additionally, all the $r$ values between SPESI and SPEI passed the significance test of $\alpha=0.05$, whilst all the $r$ values between SPESI and SSI passed the significance test of $\alpha=0.01$. In conclusion, the copula-based SPESI constructed in this paper has the characteristics of reliability, sensitivity and comprehensiveness. Combining the advantages of SPEI and SSI for capturing the occurrence and termination of drought, the SPESI can identify drought more systematically and comprehensively, and has a favourable application effect in the YRB.
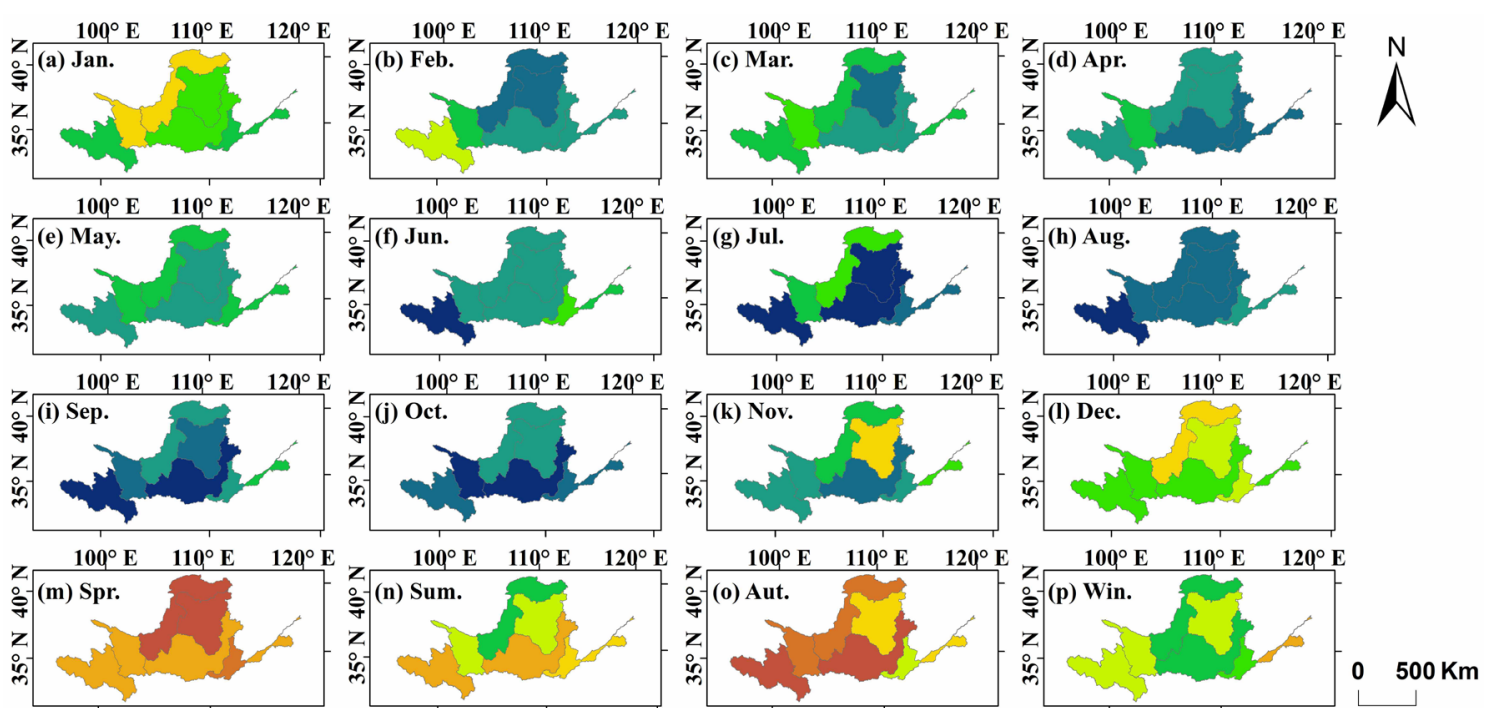

$\begin{array}{lllllllllll}0.28 & 0.34 & 0.40 & 0.46 & 0.52 & 0.58 & 0.64 & 0.70 & 0.76 & 0.82 & 0.88\end{array}$

Fig. 6. Correlations between SPESI and SPEI in the YRB from 1961 to 2015. 

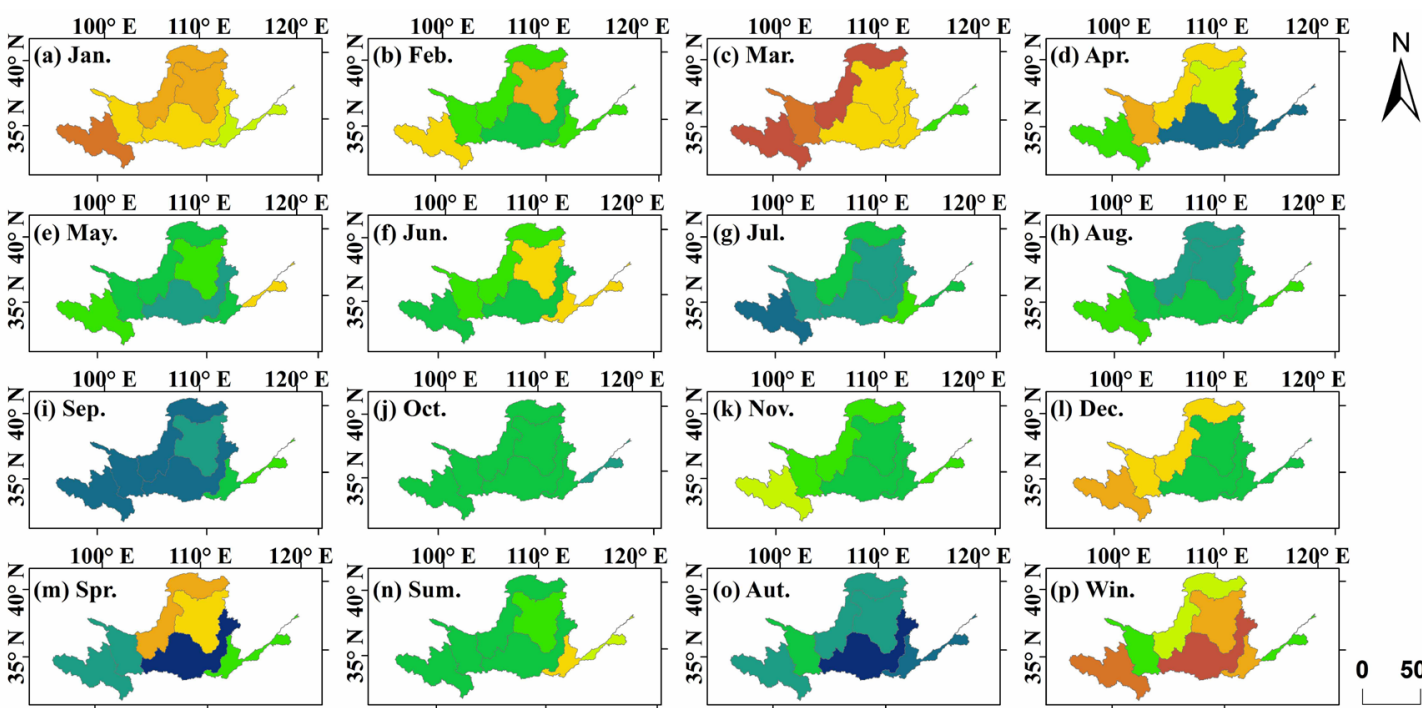

$500 \mathrm{Km}$

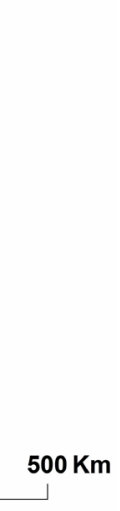

\section{Fig. 7. Correlations between SPESI and SSI in the YRB from 1961 to 2015.}

\subsection{Temporal changes and spatial features of drought}

The temporal trend characteristic $Z_{s}$ values of monthly, seasonal and annual SPESI based on the MMK trend test method are illustrated in Fig. 8. $Z_{s}>0$ shows a downward drought trend, and $Z_{s}<0$ indicates an upward drought trend. When the absolute value of $Z_{s}$ is greater than 1.96 and 2.58, the trend passes the significance test of $\alpha=0.05$ and 0.01 , respectively. It can be seen that the temporal changes of drought were obviously different in each period (Fig. 8). On the monthly scale, the $Z_{s}$ values of SPESI in the YRB from January to December were $-0.34,0.47,-1.03,-1.15,-0.58,0.10,-0.82,-0.93,-0.86,-1.08,-1.15$ and -1.28 , respectively. Drought showed an increasing trend for ten months (January, March, April, May, July, August, September, October, November and December), and a decreasing trend for the other two months (February and June) in the YRB. In addition, the $Z_{s}$ values of SPESI in each subzone were less than zero in April, July, August, September,

October and November, indicating that drought was increasing in these months. On the seasonal scale, the $Z_{s}$ values of SPESI in the YRB from spring to winter were $-4.36,-0.67$, -1.00 and -0.23 , respectively. Generally, drought showed an upward trend for each season in the YRB, with different seasonal trend characteristics in each subzone. Additionally, the 
$Z_{s}$ value in each subzone was less than zero in spring, summer and autumn, suggesting that drought was increasing in these three seasons. On the annual scale, the $Z_{s}$ value was -1.11 , indicating that drought was increasing in the YRB. Meanwhile, the $Z_{s}$ value was less than zero and drought was also increasing in each subzone. Noticeably, the $Z_{s}$ values for November in $\mathrm{HL}$ and $\mathrm{SH}$, and for spring in the entire basin passed the significance test of $\alpha=0.01$, which indicated that drought in these periods increased significantly $(P<0.01)$ in the corresponding areas. In conclusion, most of the temporal trend characteristic $Z_{s}$ values of SPESI were less than zero, indicating that drought generally showed an upward trend in the YRB during 1961-2015.

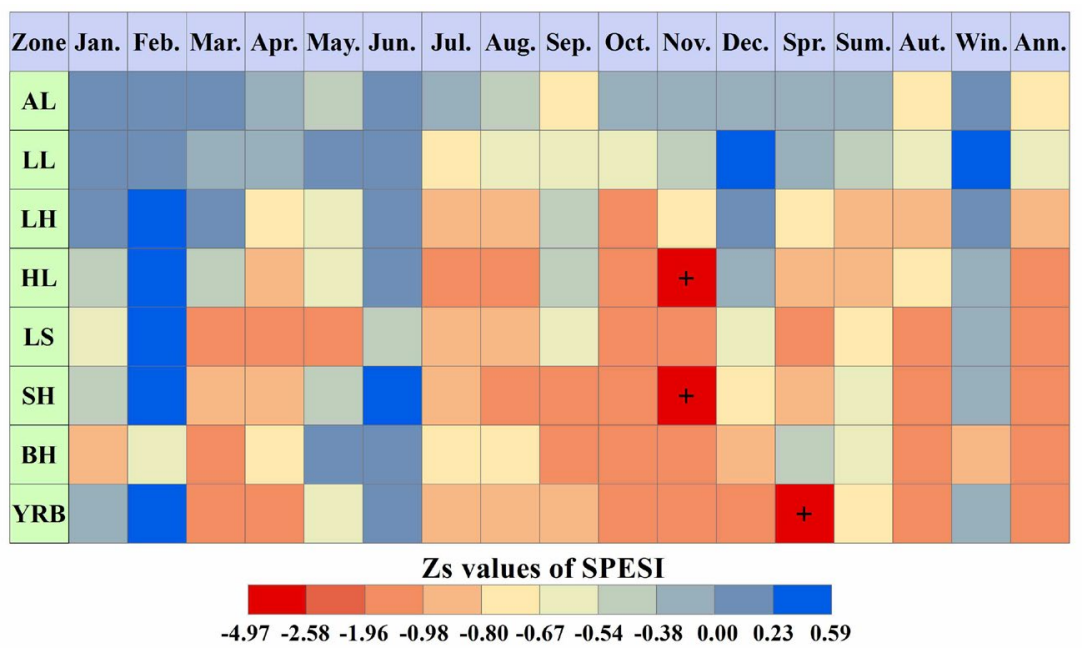

Fig. 8. $Z_{s}$ values of SPESI in the YRB during 1961-2015. “+” denotes significant at 0.01 level.

The spatial distribution characteristics of drought based on SPESI in the YRB are shown in Fig. 9, with average SPESI values for each month and season during the study period (1961-2015). On the monthly scale, the average SPESI values in the YRB from January to December were $0.06,0.11,0.05,-0.55,-1.00,-1.23,-0.57,-0.51,-0.12,-0.08$, 0.13 and 0.02 , respectively. It was concluded that the most serious drought occurred in June, followed by May. As shown in Figs. 9a-1, drought showed a slight mitigation trend from January to February, and then gradually aggravated to the worst situation in June, 
relieved from June to November, and worsened slightly from November to December. Obviously, drought occurred in almost the entire basin in June, with a minimum SPESI value of -1.61 in LH. From January to December, the worst drought with smallest SPESI values occurred in $\mathrm{AL}(-0.38), \mathrm{AL}(-0.31)$, $\mathrm{AL}(-0.08)$, $\mathrm{LL}(-0.67)$, HL (-1.36), LH $(-1.61)$, LH (-1.27), LH (-0.79), BH (-0.53), BH (-0.41), AL (-0.37) and AL (-0.48). On the seasonal scale, the average SPESI values in spring, summer, autumn and winter were $-0.65,-0.89,0.13$ and 0.21 , respectively. It could be seen that the worst drought occurred in summer, followed by spring. From spring to winter, the most serious drought with smallest SPESI values occurred in HL (-0.83), LH (-1.43), BH (-0.26) and AL $(-0.56)$. Drought monitoring should be emphasized in the months and seasons with relatively severe drought situation in each subzone. Furthermore, relevant drought-resistant actions should be adopted and preventive measures for drought mitigation should be formulated, in order to improve the ability to resist drought disasters.
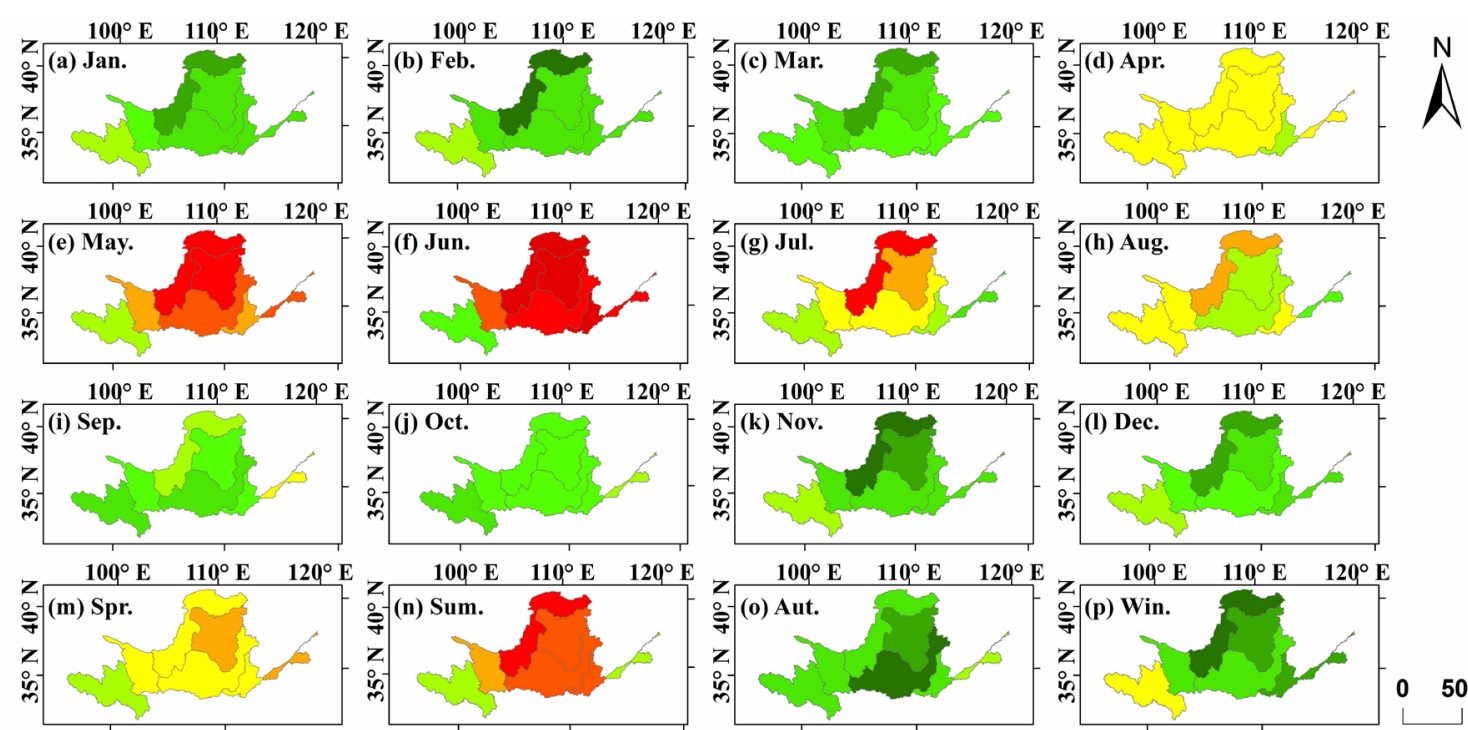

$500 \mathrm{Km}$

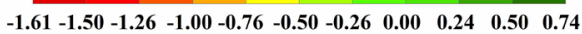

Fig. 9. Spatial distribution of SPESI in the YRB.

\subsection{Drought return period}

Drought duration and severity were identified based on run theory in the YRB during 
with the best GOF were selected as the marginal distributions of drought duration and severity. Before establishing the copula joint distribution function, the correlation test of drought duration and severity was carried out. The calculated $\tau$ and $\rho_{s}$ between drought duration and severity were above 0.79 and 0.92 , respectively; and all correlation coefficients passed the significance test of $\alpha=0.01$, indicating that there was a good correlation between drought duration and severity in the YRB. The existence of strong correlation provided a precondition for describing the dependent relationship between drought duration and severity by using copula function. Therefore, five commonly used copulas (Normal-copula, t-copula, Clayton-copula, Frank-copula and Gumbel-copula) were selected to construct the joint distribution functions, after fitting the optimal marginal distribution functions of drought duration and severity in the YRB. Similarly, the GOF of copula was tested by calculating RMSE, AIC and BIC values between empirical and theoretical copula functions, in order to determine the optimal copula function of drought duration and severity. Overall, the optimal copula was Frank-copula in six subzones (AL, LH, HL, LS, SH and BH) and the entire basin, and was Normal-copula in one subzone (LL). The GOF evaluation indicators of the selected optimal copula met the requirements, thus, the selected copula functions were regarded as the joint distribution functions of drought duration and severity. From the obtained copula functions, we could see that Frank-copula was considered to be the best-fitted copula in the YRB.

Fig. 10 illustrates the drought return period based on the selected copula. In AL, LL, LH, HL, LS, SH, BH and YRB, the number of identified drought events from 1961 to 2015 was $60,61,75,70,76,71,60$ and 73 , respectively. The average drought duration and severity were 6.38 months and 6.89 in the YRB. Additionally, within the range of drought duration less than 20 months and drought severity less than 20, a total of 67 drought events occurred, with drought return period ranging from 0.75 to 8.86 years in the YRB. Figs. 
10a-g demonstrates the drought return period in each subzone. Specifically, there was one drought event with drought return period exceeding 50 years (72.32 years) in LS. The average drought duration reached a maximum value (7.60 months) in AL and a minimum value (5.14 months) in LS, with a difference of 2.46 months. And the average drought severity reached a maximum value (8.85) in AL and a minimum value (5.69) in LS, with a difference of 3.16. In summary, with the enhancement of drought duration and severity, the frequency of drought events decreased gradually, and the corresponding drought return period increased and drought disaster tended to be serious. Drought occurred more frequently with drought return period less than 10 years in the YRB.
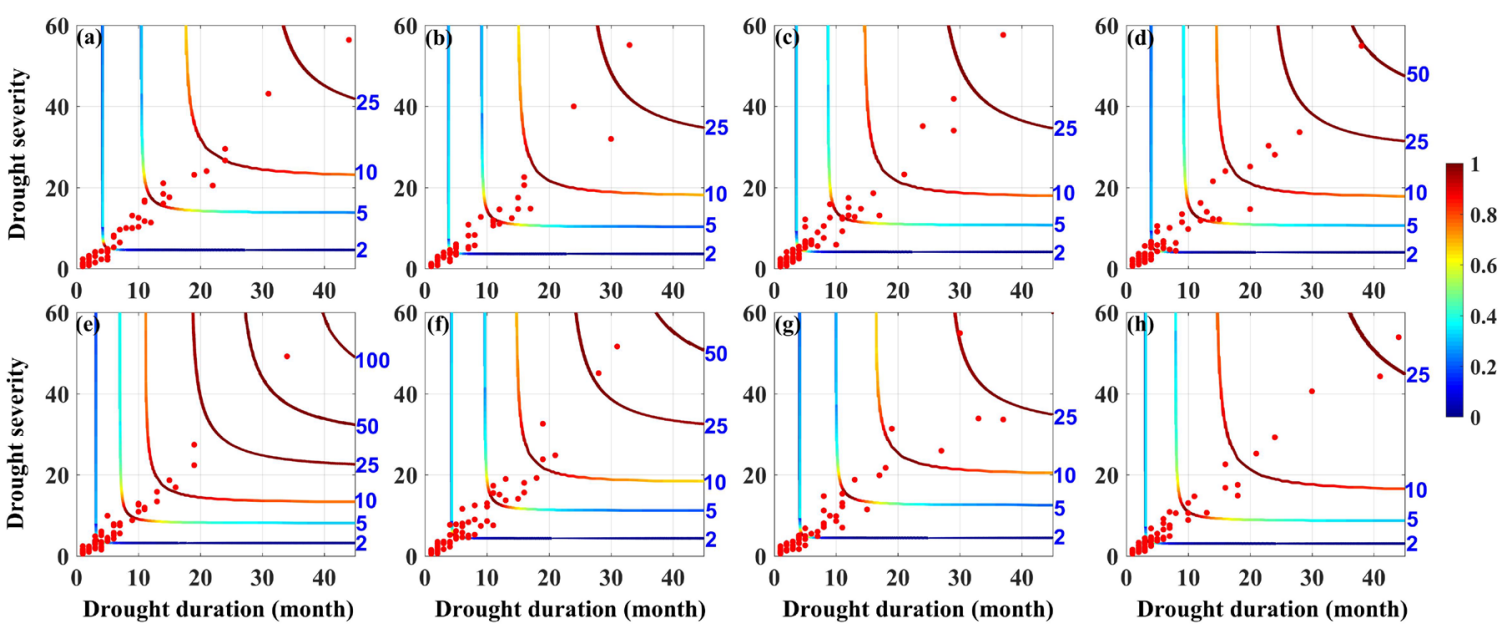

Fig. 10. Drought return period isolines (unit: year) are color coded with joint density levels with blue denoting lower densities and red representing higher densities. Red dots indicate drought events. (a)-(h) denote AL (Frank-copula), LL (Normal-copula), LH (Frank-copula), HL (Frank-copula), LS (Frank-copula), SH (Frank-copula), BH (Frank-copula) and YRB (Frank-copula), respectively.

\subsection{The links between SPESI and teleconnection factors}

It is well understood that droughts are closely related to teleconnection factors (Trenberth and David, 2001; Mishra and Singh, 2010; Huang et al., 2015a; Han et al., 2019). Thus, in order to reveal the possible links between drought and teleconnection factors, the ENSO, PDO, AO and sunspot data were selected to characterize the influences 
of large-scale climate indices on drought in the YRB. Cross wavelet transform method was adopted to reveal the links between SPESI and climate indices in the YRB during 1961-2015 (Fig. 11). In order to avoid boundary effect and high frequency false information of the wavelet transform, the thin solid line in the figure is the boundary of the cone of influence, with the effective spectral region within it. As shown in Fig. 11a, ENSO has a statistically significant negative correlation with SPESI series at the $95 \%$ confidence level, with a 24-48 month signal in 1964-1975, a 16-24 month signal in 1971-1975, and a 36-64 month signal in 1983-1997. Fig. 11b indicates that PDO has a statistically significant negative correlation with SPESI series at the 95\% confidence level, with a 30-48 month signal in 1965-1970, and a 48 month signal in 1986-1995. Fig. 11c shows that AO has a statistically significant positive correlation with SPESI series at the $95 \%$ confidence level, with a 30-54 month signal in 1964-1972, and a 36-110 month signal in 1975-1993. In addition, it can be easily observed from Fig. 11d that sunspot has a statistically significant negative correlation with SPESI series at the 95\% confidence level, with a 96-120 month signal in 1973-1982; whilst it has a statistically significant positive correlation with SPESI series at the 95\% confidence level, with a 96-120 month signal in 1983-1991. Besides, there are short-term intermittent resonance periods of 4-16 months between SPESI series and ENSO, PDO and AO, and periods of 1-8 months between SPESI series and sunspot from 1961 to 2015. In conclusion, the cross wavelet transforms can better reflect the links between drought and teleconnection factors in the YRB. ENSO and PDO have statistically significant negative dependence with SPESI, and AO has statistically significant positive dependence with SPESI, suggesting that they play an important role in the evolution of drought in the YRB. As for sunspot, it has a statistically significant negative and positive correlation with SPESI in 1973-1991. Moreover, teleconnection factors have strong influences on drought in the YRB, and the impacts of ENSO, AO and sunspot on the droughts are stronger than those of PDO. 

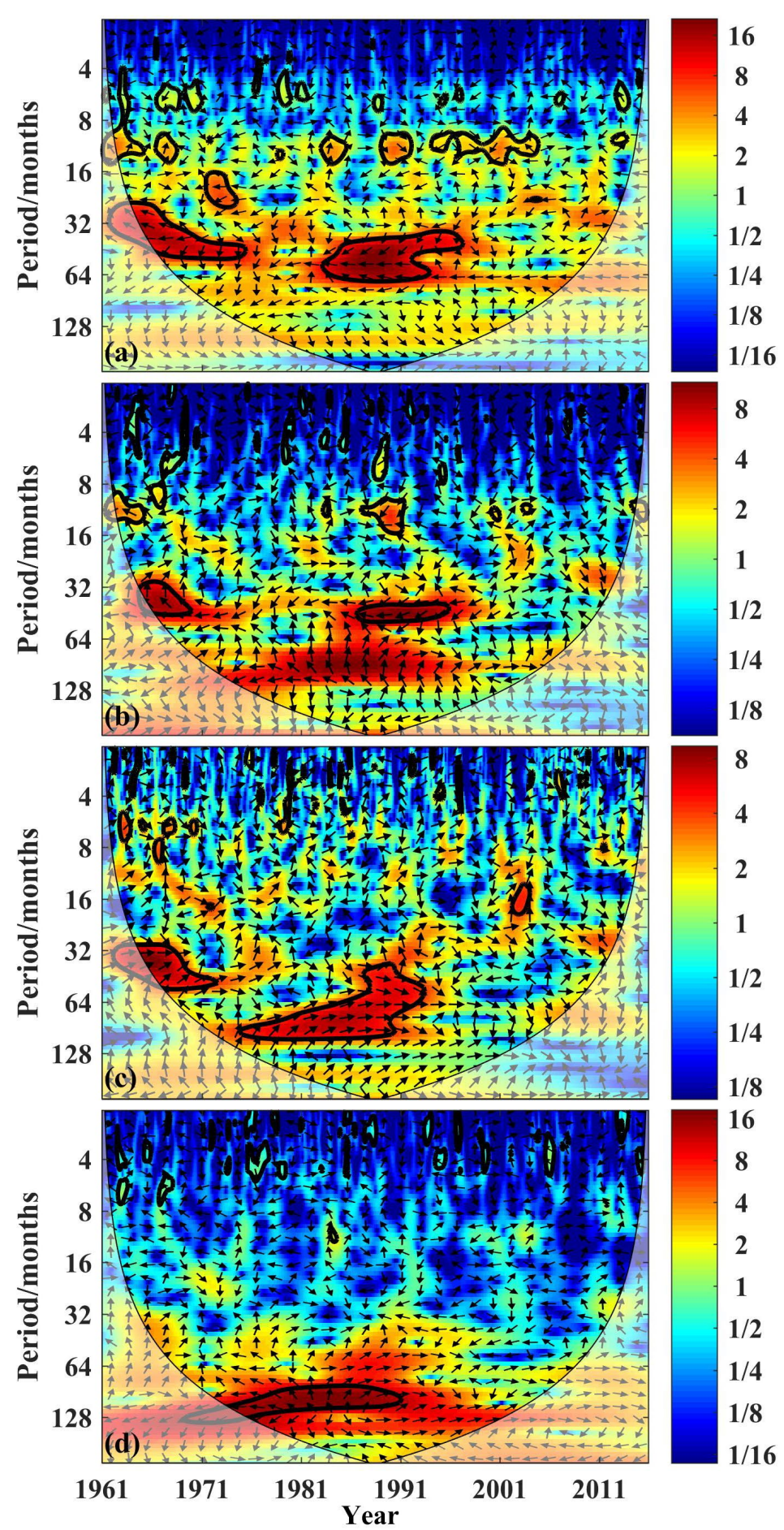

Fig. 11. The cross wavelet transforms between the monthly SPESI and ENSO (a),

511 PDO (b), AO (c) and sunspot (d) data during 1961-2015 in the YRB, respectively.

512 The $95 \%$ confidence level against red noise is exhibited as a thick contour, and the

513 relative phase relationship is denoted as arrows (with negative correlations pointing

514 left, and positive associations pointing right). The color bar on the right denotes the wavelet energy. 


\section{Discussion}

\subsection{Possible causes of drought}

With the impact of global climate change and human activities, drought has a crucial impact on human production and life; thus, it is of great practical significance to further explore the possible causes of drought in the YRB (Huang et al., 2019). In recent years, the rise of temperature $\left(0.316{ }^{\circ} \mathrm{C} / 10 \mathrm{a}\right)$ and the decline of precipitation $(-5.123 \mathrm{~mm} / 10 \mathrm{a})$ are one of the main causes of drought in the YRB (Zhang et al., 2014; Miao et al., 2016; Wang et al., 2018). In addition to the causes of climate change, human activities can also contribute to the development of drought by changing the underlying surface of river basins. The increase of water consumption in daily life of residents and over-exploitation of water resources generated by the sustained population growth, excessive greenhouse gases produced by rapid economic development, reduction of runoff amount and groundwater level due to essential irrigation water, and acceleration of evapotranspiration caused by the construction of dams and reservoirs will reduce the drought resistance and promote the drought formation in the YRB (Fu et al., 2004; Dai, 2011; Zhu et al., 2015). Over-utilization of water resources for irrigation under long-term rainless conditions will lead to more acute contradiction between supply and demand of water resources, and further increase the possibility of serious drought disasters (Shi et al., 2017). Furthermore, the terrestrial water storage is gradually decreasing in the YRB, which also makes the basin face the threat of drought (Lin et al., 2019).

Zhu et al. (2015) investigated that there was less precipitation in spring with greater interannual variations, and large crop water requirement in summer with the highest temperature and evapotranspiration, resulting in the serious drought occurred in spring and summer in the YRB, which was similar to the results of the present study. Moreover, the risk of drought is higher during spring and summer in the YRB, which is also closely 
related to ENSO events (Elizabeth et al. 2018; Ma et al., 2018; Huang et al., 2019). The onset of ENSO events including El Niño and La Niña mostly occurs in spring and summer. El Niño occurred in the tropical Pacific weakens the East Asian summer monsoon and the subtropical high in the northwestern Pacific, resulting in inadequate water vapor transport to the YRB, which eventually causes drought (Huang et al., 2019). As for La Niña, it weakens the transport capacity of the two water vapor routes from southeast and southwest and directly leads to drought (Dai and Wigley, 2000).

With regard to the teleconnection factors influencing drought, people have gradually realized that the large-scale climate indices play an important role in the drought formation (Dai, 2011). Furthermore, as found in Section 4.5, the results of cross wavelet transform also exhibited that teleconnection factors (ENSO, PDO, AO and sunspot) had strong impacts on drought evolutions. Overall, climate change and human activities in recent decades are the prime causes of drought in the YRB.

\subsection{Uncertainties}

Several areas of uncertainty were encountered in this study. First, the constructed SPESI can reflect both meteorological and hydrological drought conditions. During the construction of SPESI, the SPEI was selected as a meteorological drought index, and the SSI was chosen as a hydrological drought index. SPEI combines precipitation and evapotranspiration factors, and has the characteristics of multi-time scale (Vicente-Serrano et al., 2010). SSI reflects direct evidence of surplus and deficit in water availability under the impacts of climate variation and human activity (Gosling, 2014; Rivera et al., 2017). In addition, they are all standardized drought indices, which can be used to compare drought objectively on the spatio-temporal scale. Second, choosing different distribution functions to calculate SPEI and SSI would lead to different results. This study focused on six three-parameter distributions (P-III, Log-L, Wbl, GP, GEV and Logn). These distributions were selected because they had met the requirements and could accommodate all 
magnitudes of non-negative skewness from zero to severe (Vicente-Serrano et al., 2012). Finally, five commonly used copula functions were selected as joint distribution functions (Table 1). These copula functions are prime candidates and have been widely applied in frequency analysis (Guo et al., 2019a; Wang et al., 2019a). Moreover, there are many methods for copula selection, such as RMSE, AIC, BIC, Nash-Sutcliffe efficiency criteria, etc. The different selections of copulas may result in different joint probabilities. The RMSE, AIC and BIC were adopted for copula selection, which could obtain the favourable copula (Fan et al., 2018).

\subsection{Advantages and limitations}

Many new drought indices have been developed to monitor drought in previous studies (Hao and AghaKouchak, 2013, 2014; Huang et al., 2015a, 2019; Waseem et al., 2015; Liu et al., 2019; Guo et al., 2019a, 2019b), however, an integrated drought index constructed by combining SPEI and SSI based on copula function has not been explored, which can simultaneously represent meteorological and hydrological drought. Consequently, a copula-based SPESI was proposed to comprehensively describe the drought characteristics in the YRB. Because of the large geographical scope of the YRB, the P-PET and streamflow distribution will show regional differences, so fitting the optimal distribution function of P-PET and streamflow data before calculating SPEI and SSI can make the results more accurate (Vicente-Serrano et al., 2012; Bloomfield and Marchant, 2013; Peña-Gallardo et al., 2019). In this study, most of the optimal distribution functions of P-PET and streamflow data calculated were Log-L and GEV, which were consistent with the results of Vicente-Serrano et al. (2012) and Wang et al. (2019a).

As found in Fig. 5, SPESI can monitor the occurrence of meteorological drought (see rectangular box d) or hydrological drought (see rectangular box c) or both types of drought (see rectangular boxes a, e and f). As shown in the black rectangular box b in Fig. 5, for the drought that occurred in the middle of 1998, the drought onset is first captured by the 
SPESI while neither SPEI nor SSI indicate the drought onset. However, both indicators are decreasing and show signs of deficit. For this reason, SPESI can improve earlier detection of droughts than each individual index. Therefore, we believe that the proposed integrated index has a practical application. Once a drought is detected by SPESI, the practitioners, watershed managers or agencies should be vigilant to warn and prevent the possible coming drought. In addition, SPESI was significantly correlated $(P<0.05)$ with SPEI and SSI, indicating the preferable reliability of SPESI (Figs. 6-7). Relevant references reported that serious drought disasters occurred in 1997 and 2000 in the YRB (Wang et al., 2018, 2019a; Zhu et al., 2018). The drought captured by SPESI in this study coincided with the actual drought events, and both serious drought events in 1997 and 2000 were accurately identified (Fig. 5), suggesting that the proposed SPESI was credible and robust. Besides, Hao and AghaKouchak (2013) also compared a new comprehensive drought index with SPI and Standardized Soil Moisture Index by analyzing the occurrence and propagation time of drought captured by them, and verified that the copula-based comprehensive drought index was reliable and has an effective drought warning ability. In particular, the red line representing the SPESI is slightly lower than the other lines, suggesting that the drought conditions captured by the SPESI are a little more serious than those captured by single-element drought index (Fig. 5). Under most conditions for which there is no accurate prediction, people prefer a forecasted drought grade higher than the actual grade, which is more favorable for making plans for drought relief and prevention (Hao and AghaKouchak, 2013). Therefore, there is also a practical need to use SPESI analysis assessments to forecast droughts. Huang et al. (2015b) pointed out that drought in the YRB had been increasing in recent decades, which was consistent with the temporal trend of drought based on SPESI. Moreover, related studies (Zhu et al., 2015; Wang et al., 2018, 2019a; Huang et al., 2015a, 2019) disclosed that the worst drought occurred in summer in the YRB, followed by spring, which was similar to the results of this study, and further verified the 
adaptability of SPESI in this region. Generally, SPESI was suitable for capturing the occurrence, duration and termination of drought, and was also an effective tool for monitoring and predicting drought. In conclusion, an integrated drought index (SPESI) considering both meteorological and hydrological factors was introduced in this study to supplement the traditional drought index. This approach can provide a more reasonable and favourable drought index for administrators, which can also be applied in other geo-graphical regions.

The results of copula GOF indicated that the optimal copula function was Frank-copula in the YRB. The drought return period identified by copula function is an important metric for evaluating the magnitude of drought events, which can provide more scientific guidance for drought mitigation and prevention (Salvadori and De Michele, 2015; Ayantobo et al., 2018). Furthermore, the relationships between SPESI and large-scale climate indices indicated that teleconnection factors had significant impacts on drought in the YRB. The impacts of ENSO, AO and sunspot on the droughts were stronger than those of PDO in the YRB, which was consistent with the findings of Guo et al. (2019b). ENSO events have a strong impact on droughts in the YRB, with a signal ranging from 24 to 64 months, which is consistent with ENSO periodicity of 2-7 years (Dash et al., 2013; Huang et al., 2019). In addition, on the short period, ENSO and AO have obvious influence on drought in the YRB. On the long period (10-11years), as Fig. 11d shows, sunspot has the strongest correlation with SPESI, which is consistent with sunspot periodicity of approximately 11 years (Hathaway et al., 2002; Guo et al., 2019b). Generally, teleconnection factors are usually prior to the onset of the drought, and show closely correlations with the drought evolution. Therefore, they can be used as input factors of drought early warning systems for enhancing the accuracy in drought prediction (Huang et al., 2019). 
Although meteorological and hydrological drought were considered in this paper, agricultural and socio-economic drought should also be taken into account in future research (Hao and AghaKouchak, 2013). Additionally, only five commonly used copulas were discussed, and other types of copulas would be the focus of future research (Fenech et al., 2015). With the increase of variables in drought research, it is necessary to integrate more variables to establish joint functions among multi-variables, and the application of high-dimensional copula will become a new research direction (Oh and Patton, 2016).

\section{Conclusions}

In this paper, a new copula-based comprehensive drought index (SPESI) was proposed, which had the sensitivity of SPEI in identifying the occurrence of drought, and the strength of SSI in measuring the duration and termination drought. SPESI combined the advantages of SPEI and SSI, and could better synthetically characterize meteorological and hydrological drought. The temporal change, spatial distribution and return period of drought were comprehensively identified in the YRB during 1961-2015. Additionally, the links between SPESI and teleconnection factors were revealed using cross wavelet transform method. The primary conclusions are as follows:

(1) The optimal distribution function of monthly P-PET and streamflow data were obtained to calculate SPEI and SSI, in order to make the results have better mathematical and statistical theory basis. Subsequently, a new copula-based SPESI was proposed, which combined the advantages of SPEI and SSI, and could simultaneously reflect both meteorological and hydrological drought. The results showed that the SPESI combined both meteorological and hydrological factors, and had excellent performance ability for drought.

(2) The seasonal and annual droughts were increasing in the YRB during 1961-2015, with different temporal change characteristics in each subzone. The month and season with the most serious drought was June and summer, with an average SPESI value of -1.23 and 
-0.89. Additionally, the optimal marginal distribution function of drought duration and severity was obtained, and the drought return period was investigated based on copula function in the YRB. From the obtained copula functions, we can see that Frank-copula was considered to be the best-fitted copula in the YRB. With the enhancement of drought duration and severity, the frequency of drought events decreased gradually, and the corresponding drought return period increased and drought disaster tended to be serious. Drought occurred more frequently with drought return period less than 10 years in the YRB.

(3) The cross wavelet transforms can better reflect the links between drought and teleconnection factors in the YRB. ENSO and PDO have statistically significant negative dependence with SPESI, and AO has statistically significant positive dependence with SPESI, suggesting that they play an important role in the evolution of drought in the YRB. As for sunspot, it has a statistically significant negative correlation with SPESI in 1973-1982 and a positive correlation with SPESI in 1983-1991. Teleconnection factors have strong influences on drought in the YRB, and the impacts of ENSO, AO and sunspot on the droughts are stronger than those of PDO.

\section{Acknowledgments}

This research was supported by National Key R\&D Program of China (grant number 2018YFC0406505), Key Scientific Research Projects of Henan Colleges and Universities (grant number 19A170014), Henan Province Scientific and Technological Project (grant number 172102410075), the Open Research Fund of the State Key Laboratory of Simulation and Regulation of Water Cycle in River Basin at the China Institute of Water Resources and Hydropower Research (grant number IWHR-SKL-201701), the National Natural Science Foundation of China (grant number 51779093), and Science and technology project of Guizhou Province Water Resources Department (grant number KT201705). 


\section{References}

AghaKouchak, A., Feldman, D., Hoerling, M., Huxman, T., Lund, J., 2015. Recognize anthropogenic drought. Nature 524, 409-411.

Alam, N.M., Sharma, G.C., Moreira, E., Jana, C., Mishra, P.K., Sharma, N.K., Mandal, D., 2017. Evaluation of drought using SPEI drought class transitions and log-linear models for different agro-ecological regions of India. Phys. Chem. Earth 100, 31-43.

Ayantobo, O.O., Li, Y., Song, S.B., Javed, T., Yao, N., 2018. Probabilistic modelling of drought events in China via 2-dimensional joint copula. J. Hydrol. 559, 373-391.

Bloomfield, J.P., Marchant, B.P., 2013. Analysis of groundwater drought building on the standardized precipitation index approach. Hydrol. Earth Syst. Sc. 17, 4769-4787.

Chen, X., Li, F.W., Feng, P., 2018. Spatiotemporal variation of hydrological drought based on the Optimal Standardized Streamflow Index in Luanhe River basin, China. Nat. Hazards 91, 155-178.

Dai, A.G., Wigley, T.M.L., 2000. Global patterns of ENSO-induced precipitation. Geophys. Res. Lett. 27 (9), 1283-1286.

Dai, A., 2011. Drought under global warming: a review. Wires. Clim. Change 2, 45-65.

Dash, M.K., Pandey, P.C., Vyas, N.K., Turner, J., 2013. Variability in the ENSO-induced southern hemispheric circulation and Antarctic sea ice extent. Int. J. Climatol. 33, $778-783$.

Elizabeth, Z.M.Y., Fernando, R.V.J., Miguel, A.P., 2018. Linking El Nino Southern Oscillation for early drought detection in tropical climates: the Ecuadorian coast. Sci. Total Environ. 643, 193-207.

Fan, L.L., Wang, H.R., Liu, Z.P., Li, N., 2018. Quantifying the relationship between drought and water scarcity using copulas: case study of Beijing-Tianjin-Hebei metropolitan areas in China. Water 10, 1622. 
Fenech, J.P., Vosgha, H., Shafik, S., 2015. Loan default correlation using an Archimedean copula approach: A case for recalibration. Econ. Model. 47, 340-354.

Fu, G.B., Chen, S.L., Liu, C.M., Shepard, D., 2004. Hydro-climatic trends of the Yellow River Basin for the last 50 years. Clim. Change 65, 149-178.

Gosling, R., 2014. Assessing the impact of projected climate change on drought vulnerability in Scotland. Hydrol. Res. 45, 806-816.

Guo, Y., Huang, S.Z., Huang, Q., Wang, H., Wang, L., Fang, W., 2019a. Copulas-based bivariate socioeconomic drought dynamic risk assessment in a changing environment. J. Hydrol. 575, 1052-1064.

Guo, Y., Huang, S.Z., Huang, Q., Wang, H., Fang, W., Yang, Y.Y., Wang, L., 2019b. Assessing socioeconomic drought based on an improved Multivariate Standardized Reliability and Resilience Index. J. Hydrol. 568, 904-918.

Han, Z.M., Huang, S.Z., Huang, Q., Leng, G.Y., Wang, H., He, L., Fang, W., Li, P., 2019. Assessing GRACE-based terrestrial water storage anomalies dynamics at multi-timescales and their correlations with teleconnection factors in Yunnan Province, China. J. Hydrol. 574, 836-850.

Hao, Z.C., AghaKouchak, A., 2013. Multivariate Standardized Drought Index: A parametric multi-index model. Adv. Water Resour. 57, 12-18.

Hao, Z.C., AghaKouchak, A., 2014. A nonparametric multivariate multi-index drought monitoring framework. J. Hydrometeorol. 15, 89-101.

Hathaway, D.H., Wilson, R.M., Reichmann, E.J., 2002. Group Sunspot Numbers: sunspot cycle characteristics. Solar Phys. 211, 357-370.

Hosking, J.R.M., Wallis, J.R., Wood, E.F., 1985. Estimation of the generalized extreme-value distribution by the method of probability-weighted moments. Technometrics 27, 251-261. 
Hosking, J.R.M., 1986. The theory of probability weighted moments. Research Rep. RC12210, IBM Research Div., Yorktown Heights.

Hosking, J.R.M., 1990. L-moments: Analysis and estimation of distributions using linear combinations of order statistics. J. R. Stat. Soc. 52, 105-124.

Huang, S.Z., Huang, Q., Chang, J.X., Zhu, Y.L., Leng, G.Y., Xing, L., 2015a. Drought structure based on a nonparametric multivariate standardized drought index across the Yellow River basin, China. J. Hydrol. 530, 127-136.

Huang, S.Z., Chang, J.X., Leng, G.Y., Huang, Q., 2015b. Integrated index for drought assessment based on variable fuzzy set theory: A case study in the Yellow River basin, China. J. Hydrol. 527, 608-618.

Huang, S.Z., Wang, L., Wang, H., Huang, Q., Leng, G.Y., Fang, W., Zhang, Y., 2019. Spatio-temporal characteristics of drought structure across China using an integrated drought index. Agr. Water Manage. 218, 182-192.

Hudgins, L., Huang, J., 1996. Bivariate wavelet analysis of Asia monsoon and ENSO. Adv. Atmos. Sci. 13, 299-312.

Kao, S.C., Govindaraju, R.S., 2010. A copula-based joint deficit index for droughts. J. Hydrol. 380, 121-134.

Lee, T., Modarres, R., Ouarda, T.B.M.J., 2013. Data-based analysis of bivariate copula tail dependence for drought duration and severity. Hydrol. Processes 27, 1454-1463.

Li, C., Singh, V.P., Mishra, A.K., 2013. A bivariate mixed distribution with a heavy-tailed component and its application to single-site daily rainfall simulation. Water Resour. Res. 49, 767-789.

Lin, M., Biswas, A., Bennett, E.M., 2019. Spatio-temporal dynamics of groundwater storage changes in the Yellow River Basin. J. Environ. Manage. 235, 84-95. 
Liu, Y., Zhu, Y., Ren, L.L., Yong, B., Singh, V.P., Yuan, F., Jiang, S.H., Yang, X.L., 2019. On the mechanisms of two composite methods for construction of multivariate drought indices. Sci. Total Environ. 647, 981-991.

Ma, F., Ye, A.Z., You, J.J., Duan, Q.Y., 2018. 2015-16 floods and droughts in China, and its response to the strong El Niño. Sci. Total Environ. 627, 1473-1484.

Maeng, S.J., Azam, M., Kim, H.S., Hwang, J.H., 2017. Analysis of changes in spatio-temporal patterns of drought across South Korea. Water 9, 679.

Makokha, G.O., Wang, L., Zhou, J., Li, X.P., Wang, A.H., Wang, G.P., Kuria, D., 2016. Quantitative drought monitoring in a typical cold river basin over Tibetan Plateau: An integration of meteorological, agricultural and hydrological droughts. J. Hydrol. 543, 782-795.

Marcos-Garcia, P., Lopez-Nicolas, A., Pulido-Velazquez, M., 2017. Combined use of relative drought indices to analyze climate change impact on meteorological and hydrological droughts in a Mediterranean basin. J. Hydrol. 554, 292-305.

Masud, M.B., Khaliq, M.N., Wheater, H.S., 2015. Analysis of meteorological droughts for the Saskatchewan River Basin using univariate and bivariate approaches. J. Hydrol. 522, 452-466.

Miao, C.Y., Sun, Q.H., Duan, Q.Y., Wang, Y.F., 2016. Joint analysis of changes in temperature and precipitation on the Loess Plateau during the period 1961-2011. Clim Dyn. 47, 3221-3234.

Mishra, A.K., Singh, V.P., 2010. A review of drought concepts. J. Hydrol. 391, 202-216.

Mondal, A., Mujumdar, P.P., 2015. Return levels of hydrologic droughts under climate change. Adv. Water Resour. 75, 67-79.

Montaseri, M., Amirataee, B., Rezaie, H., 2018. New approach in bivariate drought duration and severity analysis. J. Hydrol. 559, 166-181. 
Oh, D.H., Patton, A.J., 2016. High-dimensional copula-based distributions with mixed frequency data. J. Econometrics 193, 349-366.

Oloruntade, A.J., Mohammad, T.A., Ghazali, A.H., Wayayok, A., 2017. Analysis of meteorological and hydrological droughts in the Niger-South Basin, Nigeria. Global Planet. Change 155, 225-233.

Peña-Gallardo, M., Vicente-Serrano, S.M., Hannaford, J., Lorenzo-Lacruz, J., Svoboda, M., Domínguez-Castro, F., Maneta, M., Tomas-Burguera, M., Kenawy, A.E., 2019. Complex influences of meteorological drought time-scales on hydrological droughts in natural basins of the contiguous Unites States. J. Hydrol. 568, 611-625.

Rajsekhar, D., Singh, V.P., Mishra, A.K., 2015. Multivariate drought index: An information theory based approach for integrated drought assessment. J. Hydrol. 526, 164-182.

Rivera, J.A., Penalba, O.C., Villalba, R., Araneo, D.C., 2017. Spatio-temporal patterns of the 2010-2015 extreme hydrological drought across the Central Andes, Argentina. Water 9, 652 .

Salvadori, G., De Michele, C., 2015. Multivariate real-time assessment of droughts via copula-based multi-site Hazard Trajectories and Fans. J. Hydrol. 526, 101-115.

Shahabfar, A., Eitzinger, J., 2013. Spatio-temporal analysis of droughts in semi-arid regions by using meteorological drought indices. Atmosphere 4, 94-112.

She, D.X., Xia, J., 2013. The spatial and temporal analysis of dry spells in the Yellow River basin, China. Stoch. Environ. Res. Risk Assess. 27, 29-42.

Sherly, M.A., Karmakar, S., Chan, T., Rau, C., 2016. Design rainfall framework using multivariate parametric-nonparametric approach. J. Hydrol. Eng. 21, 04015049.

Shi, H.L., Hu, C.H., Wang, Y.G., Liu, C., Li, H.M., 2017. Analyses of trends and causes for variations in runoff and sediment load of the Yellow River . Int. J. Sediment Res. 32, $171-179$. 
Shukla, S., Wood, A.W., 2008. Use of a standardized runoff index for characterizing hydrologic drought. Geophys. Res. Lett. 35, 1-7.

Singh, V.P., Guo, H., Yu, F.X., 1993. Parameter estimation for 3-parameter log-logistic distribution (LLD3) by Pome. Stoch. Hydrol. Hydraul. 7, 163-177.

Su, L., Miao, C.Y., Borthwick, A.G.L., Duan, Q.Y., 2017. Wavelet-based variability of Yellow River discharge at 500-, 100-, and 50-year timescales. Gondwana Res. 49, 94-105.

Telesca, L., Lovallo, M., Lopez-Moreno, I., Vicente-Serrano, S., 2012. Investigation of scaling properties in monthly streamflow and Standardized Streamflow Index (SSI) time series in the Ebro basin (Spain). Physica A. 391, 1662-1678.

Tirivarombo, S., Osupile, D., Eliasson, P., 2018. Drought monitoring and analysis: Standardised Precipitation Evapotranspiration Index (SPEI) and Standardised Precipitation Index (SPI). Phys. Chem. Earth 106, 1-10.

Torrence, C., Compo, G.P., 1998. A practical guide to wavelet analysis. Bull. Am. Meteorol. Soc. 79, 61-78.

Trenberth, K.E., David, P.S., 2001. Indices of El niño evolution. J. Clim. 14, 1697-1701.

Vicente-Serrano, S.M., Beguería, S., López-Moreno, J.I., 2010. A multiscalar drought index sensitive to global warming: The Standardized Precipitation Evapotranspiration Index. J. Clim. 23, 1696-1718.

Vicente-Serrano, S.M., López-Moreno, J.I., Beguería, S., Lorenzo-Lacruz, J., Azorin-Molina, C., Morán-Tejeda, E., 2012. Accurate computation of a streamflow drought index. J. Hydrol. Eng. 17, 318-332.

Vyver, H.V.D., Bergh, J.V.D., 2018. The Gaussian copula model for the joint deficit index for droughts. J. Hydrol. 561, 987-999. 
Wang, F., Wang, Z.M., Yang, H.B., Zhao, Y., 2018. Study of the temporal and spatial patterns of drought in the Yellow River basin based on SPEI. Sci. China Earth Sci. 61, 1098-1111.

Wang, F., Wang, Z.M., Yang, H.B., Zhao, Y., Zhang, Z.Z., Li, Z.H., Hussain, Z., 2019a. Copula-based drought analysis using standardized precipitation evapotranspiration index: A case study in the Yellow River Basin, China. Water 11, 1298.

Wang, F., Yang, H.B., Wang, Z.M., Zhang, Z.Z., Li, Z.H., 2019b. Drought evaluation with CMORPH satellite precipitation data in the Yellow River Basin by using Gridded Standardized Precipitation Evapotranspiration Index. Remote Sens. 11, 485.

Waseem, M., Ajmal, M., Kim, T., 2015. Development of a new composite drought index for multivariate drought assessment. J. Hydrol. 527, 30-37.

Yao, N., Li, Y., Lei, T.J., Peng, L.L., 2018. Drought evolution, severity and trends in mainland China over 1961-2013. Sci. Total Environ. 616-617, 73-89.

Yu, M.X., Li, Q.F., Hayes, M.J., Svoboda, M.D., Heim, R.R., 2014. Are droughts becoming more frequent or severe in China based on the Standardized Precipitation Evapotranspiration Index: 1951-2010? Int. J. Climatol. 34, 545-558.

Zhang, B.Q., He, C.S., Morey, B., Zhang, L.H., 2016. Evaluating the coupling effects of climate aridity and vegetation restoration on soil erosion over the Loess Plateau in China. Sci. Total Environ. 539, 436-449.

Zhang, Q., Peng, J.T., Singh, V.P., Li, J.F., Chen, Y.Q., 2014. Spatio-temporal variations of precipitation in arid and semiarid regions of China: The Yellow River basin as a case study. Global Planet. Change 114, 38-49.

Zhang, Y.Q., You, Q.L., Chen, C.C., Li, X., 2017. Flash droughts in a typical humid and subtropical basin: A case study in the Gan River Basin, China. J. Hydrol. 551, 162-176. 
Zhao, H.Y., Gao, G., An, W., Zou, X.K., Li, H.T., Hou, M.T., 2017. Timescale differences between SC-PDSI and SPEI for drought monitoring in China. Phys. Chem. Earth 102, 48-58.

Zhu, Y., Liu, Y., Ma, X.Y., Ren, L.L., Singh, V.P., 2018. Drought analysis in the Yellow River Basin based on a short-scalar Palmer Drought Severity Index. Water 10, 1526.

Zhu, Y.L., Chang, J.X., Huang, S.Z., Huang, Q., 2015. Characteristics of integrated droughts based on a nonparametric standardized drought index in the Yellow River Basin, China. Hydrol. Res. 287, 454-467. 